\title{
ОБЗОР И ГЕОГРАФИЯ ВИДОВ РОДА ALOPECURUS L. (POACEAE) В КЫРГЫЗСКОЙ РЕСПУБЛИКЕ
}

\author{
А. К. Усупбаев \\ Институт Биологии Наџиональной Академии наук Кыргызской Республики, Киргизия
}

Поступила в редакиию 28 января 2018 г.

\begin{abstract}
Аннотация: Приведен обзор рода Alopecurus L. (Poaceae) флоры Киргизии по материалам гербария (FRU) ИБ НАН КР с краткими номенклатурными сведениями и ключом для определения видов. Накопленные коллекции гербария института не были полностью обработаны и определены, и в подавляющей части, их не видели и систематики-монографы, работающие в других городах. Эти коллекции не были обработаны полностью также при написании «Определителя растений Средней Азии». На территории Кыргызской Республики (КР) в естественных условиях произрастают следующие виды: Alopecurus apiatus Ovcz., A. arundinaceus Poir., A. himalaicus Hook.f., A. mucronatus Hack., A. myosuroides Huds., A. pratensis Bourg. ex Lange. Впервые на территории Киргизии выявлен вид Alopecurus aequalis Sobol. Обзор сопровождается картами распространения всех видов. Распространение на территории республики приводится по ботанико-географическим районам, согласно «Кадастру...» [7]: СК - Северный Кыргызстан (Чуйская долина с прилегающим северным макросклоном хребта Киргизский Ала-Тоо и бассейн реки Чон-Кемин); ПИ - Прииссыккулье; ЦТ - Центральный Тянь-Шань; ЗТ - Западный Тянь-Шань; ПФ - Приферганские районы в пределах КР; ВТВнутренний Тянь-Шань; А - Алайская долина (включая южные склоны Алайского и северные склоны Заалайского хребтов); ВК - весь Кыргызстан, если вид отмечен во всех без исключения вышеприведенных выделах. В статью включены только те виды, которые растут в административных границах КР и относятся только к дикорастущим. Культивируемые растения здесь не представлены. Горные экосистемы Кыргызской Республики поддерживают уникальное скопление растений и животных. Всего можно выделить 22 класса экосистем и 160 разновидностей горных и равнинных ландшафтов. Они населены примерно 26500 видами живых организмов. Благодаря высокой сложности и контрастности географической среды Кыргызстана в стране наблюдается очень высокая концентрация видов. На единицу площади здесь приходится на порядок-два больше видов, чем в среднем по планете.
\end{abstract}

Ключевые слова: Alopecurus, Poасеае, Кыргызская Республика, гербарий, новые находки.

\section{The synopsis and geographyof the genus Alopecurus L. (Poaceae) in flora of Kyrgyz Republic}

\section{A.K. Usupbaev}

Abstract: Synopsis of the genus Alopecurus L. of Kyrgyz flora is presented, with brief nomenclature citations and the key for identification, which materials are kept in herbarium (FRU) of the Institute for Biology Kyrgyz National Academy of Sciences (Bishkek). Poaceae family materials are reviewed in the first time, Collections of the Institute's herbarium were not fully processed and identified and nobody not saw by taxonomists and monographs who working in other cities. These collections were not fully processed as well when writing the «Key to the Plants of Central Asia». Alopecurus apiatus Ovcz., A. arundinaceus Poir., A. himalaicus Hook.f., A. mucronatus Hack., A. myosuroides Huds., A. pratensis Bourg. ex Lange.are widely distributed in the territory of Kyrgyz Republic. Alopecurus aequalis Sobol. is newly reported for the Kyrgyzstan. The synopsis also is distributional maps, for each species. Maps of distribution for species growing in Kyrgyz Republic and list of studied specimens are provided. Spreading each species within the Kyrgyzstan territory conventional regions after the «Cadastre...» [7]. NK - Northern Kyrgyzstan; IK - Issyk-Kul Lake depression; CT - Central Tien Shan; WT - western Tien Shan; F - CisFerghanian Kyrgyzstan; IT - Inner Tien Shan; A - Alai Valley; EK - Entire territory of Kyrgyzstan. The

(C) Усупбаев А.К., 2019 
article includes only those species that grow within the administrative boundaries of the Kyrgyz Republic, as well as only natural species. Cultivated plants are not represented here. Mountain ecosystems of the Kyrgyz Republic support the unique set of plants and animals. In general, 22 classes ecosystem are distinguished, and 160 mountain and lowland varieties of landscapes could be differentiated. The territory of Kyrgyz Republic is inhabited by approximately 26500 species of living creatures. Due to the high complexity, the contrast of the geographical and environmental conditions, regional density of species (number of taxa per territory unit) here is 10-20 times larger than the global average one.

Key words: Alopecurus, Poaceae, Kyrgyz Republic, herbarium, new records.

Всего во флоре КР произрастает свыше 4100 видов сосудистых растений из примерно 875 родов и 140 семейств. Самые крупные по числу видов Asteraceae Fabaceae Poaceae включают 1300 видов, или около 1/3 флоры КР [5].

Накопленные коллекции гербария Института биологии АН Киргизской ССР не были полностью обработаны и определены, и в подавляющей части, их не видели и систематики-монографы, работающие в других городах. Эти коллекции не были обработаны полностью также при написании «Определителя растений Средней Азии» [4].

Согласно Н.Н. Цвелеву [19], около 50 видов рода Alopecurus L., разделены на несколько секций и распространены почти во всех внетропических странах обоих полушарий, а отчасти также в высокогорьях тропиков. На территории бывшего СССР отмечено 20 видов.

Во «Флоре Киргизской ССР» [10] род Alopecurus L. был обработан Е.В. Никитиной. Сведения, приведенные в этом издании, заметно устарели, так как за годы, прошедшие со времени публикации этой сводки, был накоплен большой фактический материал по данному роду, требующий критической ревизии. Поэтому нами проведена ревизия рода Alopecurus L. во флоре Кыргызской Республики. Составлен конспект рода, включающий в себя 7 дикорастущих видов и ключ для их определения.

\section{МАТЕРИАЛЫ И МЕТОДЫ ИССЛЕДОВАНИЙ}

Настоящая статья основана на материалах гербария (примерно 500 образцов рода Alopecurus) института Биологии Национальной Академии наук KP (FRU), а так же собственных сборов из разных ботанико-географических районов республики.

При определении гербарных образцов использовались сводки $[19,10,2,3,11,12$, 9]. В результате исследования составлен конспект видов рода, встречающихся на территории КР. Сведения по описанию, распространению и местообитанию каждого вида приводится только по основным литературным источникам «Флора СССР» [11], «Фло- ра Киргизской ССР» [10], «Определитель растений Средней Азии» [9], а также монография Н.Н. Цвелева «Злаки СССР» [19].

Составлен ключ для определения видов, встречающихся на территории КР, по данным литературы $[19,10,9,11]$. Карты-схемы распространения видов выполнены точечным методом. Распространение видов на территории КР приводится по ботанико-географическим районам, согласно «Кадастру...» [7]. Для каждого вида цитируются типовые образцы или данные протолога о классическом местонахождении по Н.Н. Цвелеву [19]. Для видов, впервые приводимых для территории республики, цитируются этикетки. Римскими цифрами указывается месяцы цветения и плодоношения. При необходимости виды снабжены примечаниями. До сих пор семейство Роасеае, в том числе род Alopecurus, в крупнейшем Гербарии республики ИБ НАН КР (FRU) не подверглось ревизии $[13,14$, $15,16,17,18,8]$. Семейство Роасеае является одним из крупнейших семейств однодольных и их таксономическое изучение еще не завершено. Особенно это касается многих территорий Азии [19, $10,6,1,20,21,22,23]$.

\section{РЕЗУЛЬТАТЫ ИССЛЕДОВАНИЯ И ОБСУЖДЕНИЕ}

В результате исследования составлен конспект видов рода, встречающихся на территории КР. В статью включены только дикорастущие виды, которые произрастают в административных границах КР. Культивируемые растения здесь не представлены. Составлен конспект рода, включающий 7 дикорастущих видов и ключ для их определения. Впервые на территории Киргизии выявлен вид Alopecurus aequalis Sobol.

\section{Ключ для определения видов}

1. Колосковые чешуи с крылатым (крыло 0,20,5 мм шир.) килем, тонкокожистые

7. A. myosuroides

+ Колосковые чешуи бескрылым или почти бескрылым (крыло до 0,1 мм шир.) килем, кожисто-перепончатые или перепончатые ................ 2 
2. Однолетние или малолетние растения с коленчато согнутыми, часто восходящими или лежачими стеблями 6. A. aequalis

+ Многолетние растения с прямостоячими стеблями

3. Верхушки колосковых чешуй не отогнутые кнаружи, как бы сходящиеся ........ 5. A. pratensis

+ Верхушки колосковых чешуй заметно отогнутые кнаружи, как бы расходящиеся в стороны ....... 4

4. Растения, образующие рыхлые дерновины с короткими ползучими подземными побегами

1.A. himalaicus

+ Растения с длинными ползучими подземными побегами, не образующие дерновин ............... 5

5. Колосковые чешуи со стороны, обращенной к оси метелки, сросшиеся краями друг с другом на 1/5-1/7 длины

4. A. arundinaceus

+ Колосковые чешуи со стороны, обращенной к оси метелки, сросшиеся краями друг с другом на 1/3-1/4 длины

... 6

6. Колосковые чешуи почти по всей наружной поверхности б. м. волосистые .. 2.A. mucronatus

+ Колосковые чешуи обычно только по жилкам волосистые 3.A. apiatus

\section{Конспект видов рода Alopecurus (Poaceae)}

С е к ц и я 1 . Colobachne (Beauv.) Griseb.

1. A. himalaicus Hook. 1896, Fl. Brit. India [J. D. Hooker] 7(22): 238; Овчинников, 1934, во Флоре СССР, 2: 144; Набиев, 1968, в Определителе растений Средней Азии, 1: 93; Цвелев, 1976, Злаки СССР, 374. - Л. гималайский.

Описан с Гималайских гор [19].

VII-VIII. Альпийский пояс гор; луга (пойменные), петрофитные группировки (каменистые, осыпи, щебнистые осыпи, каменисто-щебнистые осыпи, скалы).

Распространение - КР (Карта 4): 3Т.

- Общее: Средняя Азия (ТШ-Таласский, Пскемский хребты, Гисс.-Дарв., Памир), Иран, Гималаи [19].

С е к ц и я 2 .Alopecurus.

2. A. mucronatus Hack. 1903, Vidensk. Meddel. Naturhist. Foren. Kjobenhavn, 162 (163); Овчинников, 1934, во Флоре СССР, 2: 146, табл. 10, рис. 15; Набиев, 1968, в Определителе растений Средней Азии, 1: 93; Цвелев, 1976, Злаки СССР, 374. Л. остроконечный.

Описан с Памира. Изотип (Цвелев, 1976): «Pamir, Tschatir-Tash, 4000 m, 14.VII.1898, n 772, O. Paulsen» (LE) [19].
VII-VIII. Альпийский пояс гор; луга (пойменные).

Распространение - КР (Карта 5): 3Т.

- Общ ее: Средняя Азия (ТШ перевал Арашан Чаткальского хребта, Памир) [19]. Субэндемик.

3. A. apiatus Ovcz. 1934, Во Флоре СССР, 2: 146, 744; Овчинников, 1934, во Флоре СССР, 2: 146, табл. 10, рис. 16; Е. Никитина, 1950, во Флоре Киргизской ССР. 2: 72, табл. 13, рис. 2; Набиев, 1968, в Определителе растений Средней Азии, 1: 93; Цвелев, 1976, Злаки СССР, 375. - Л. пестрый.

Описан с Алайского хребта. Тип (Цвелев, 1976): «JugumAlaicum, pгоpe st. Sary-tasch, in pratis, 10 400', 2.VII.1901, n 1355, Th. Alexeenko» (LE) [19].

VII-VIII. Альпийский пояс гор; луга (пойменные), петрофитные группировки (каменистые, осыпи, щебнистые осыпи).

Распространение - КР (Карта 2): 3Т, А.

- Общее: Средняя Азия (ТШ зап., Гисс.-Дарв.), Иран, Гималаи [19].

4. A. arundinaceus Poir. 1808, Encycl. [J. Lamarck \& al.] 8: 766; - Alopecurus ventricosus Pers.: Овчинников, 1934, во Флоре СССР, 2: 149; Е. Никитина, 1950, во Флоре Киргизской ССР. 2: 72; Набиев, 1968, в Определителе растений Средней Азии, 1: 93. - Alopecurus arundinaceus subsp. arundinaceus (Poir.) Tzvel. 1976, Злаки СССР, 375.

\section{- Л. тростниковидный.}

Описан по культивировавшимся экземплярам, вероятно, происходящим из Передней Азии [19].

VI-VIII. Пояс долин низкогорий и предгорий, средний пояс гор; луга (пойменные, мезофитные, высокотравные, разнотравные), болота, берега рек, озер и водоемов, пески (приречные), галечники (приречные), солончаки.

Распространение. - КР (Карта 3): СК, ПИ, ЗТ, ПФ, ВТ, А.

- Общее: Средняя Азия (ТШ, Арало-Каспий, Прибалхашье, Джунгар-Тарбагатай, Кызылкум, Сырдарья, Амударья, Гисс.-Дарв., Памир., Туркмения), Кавказ, Западная Сибирь, Восточная Сибирь, Дальний Восток, Скандинавия, Атлантическая Европа, Средняя Европа, Восточная Европа, Средиземноморье, Малая Азия, Иран, Гималаи, Джунгар-Кашгар, Монголия [19].

5. A. pratensis Bourg. ex Lange, 1864, Bull. Soc. Bot. France 11: 47; Овчинников, 1934, во Флоре СССР, 2: 150, табл. 11, рис. 2,3; Е. Никитина, 1950, во Флоре Киргизской ССР. 2: 75, табл. 13, рис. 2; Набиев, 1968, в Определителе растений Средней Азии, 1: 94. - Alopecurus pratensis subsp. pratensis 


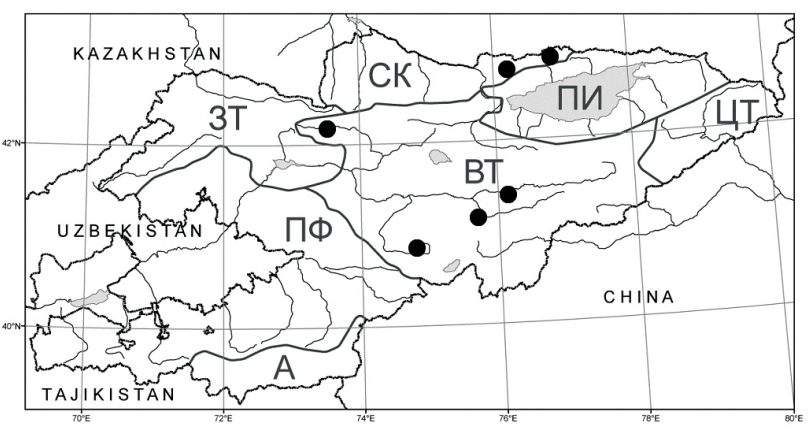

Карта 1. Alopecurus aequalis

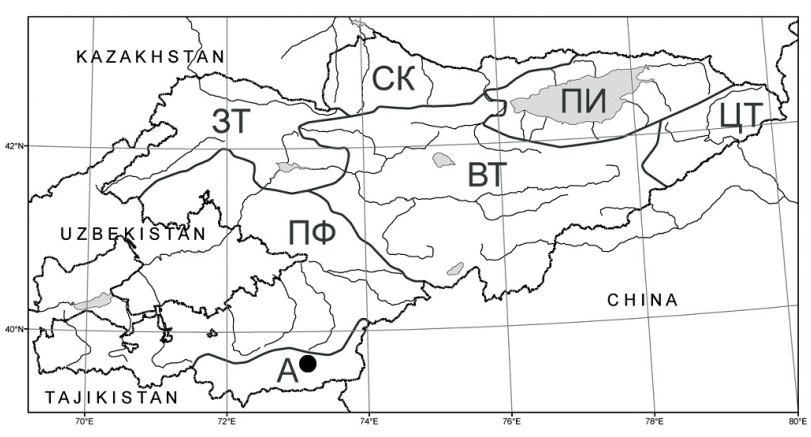

Карта 2. Alopecurus apiatus

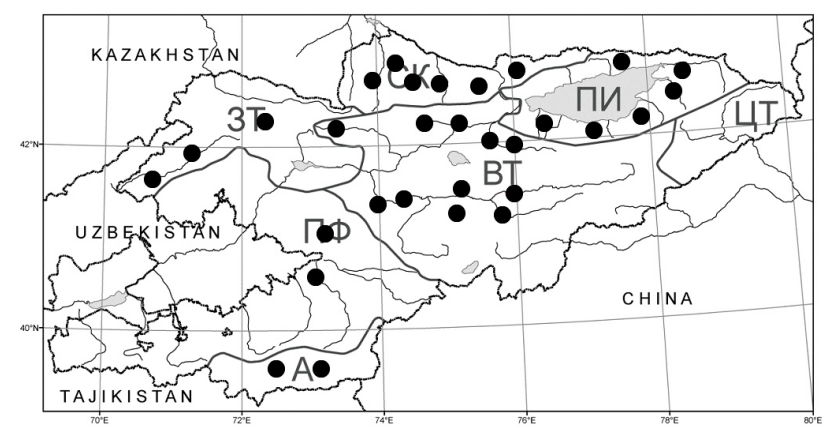

Карта 3. Alopecurus arundinaceus

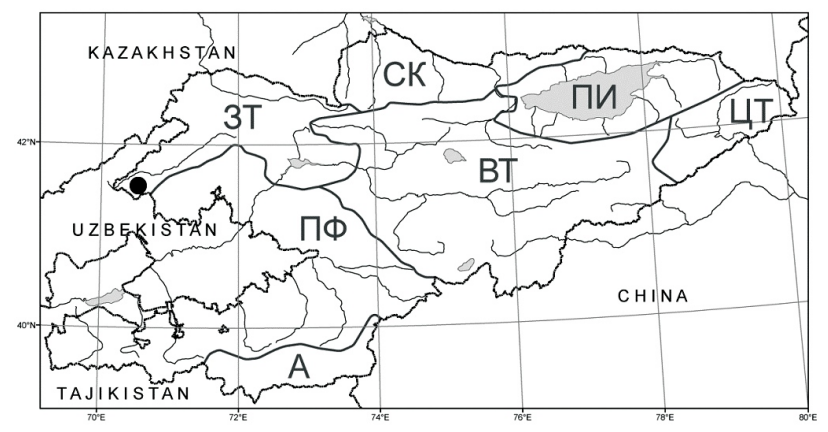

Карта 4. Alopecurus himalaicus

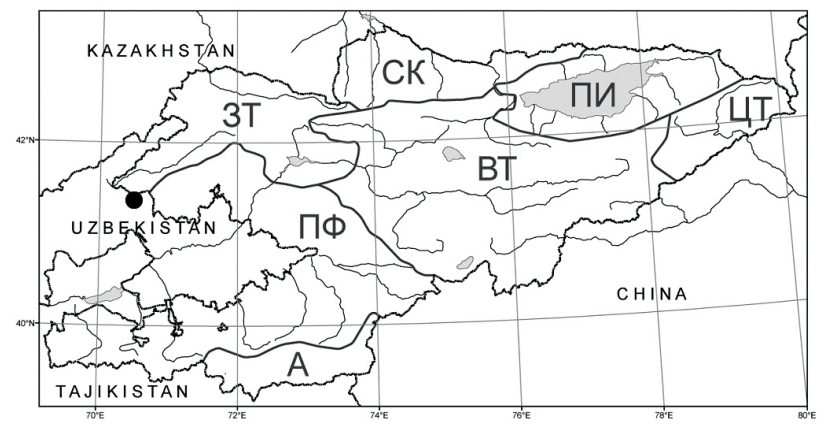

Карта 5. Alopecurus mucronatus

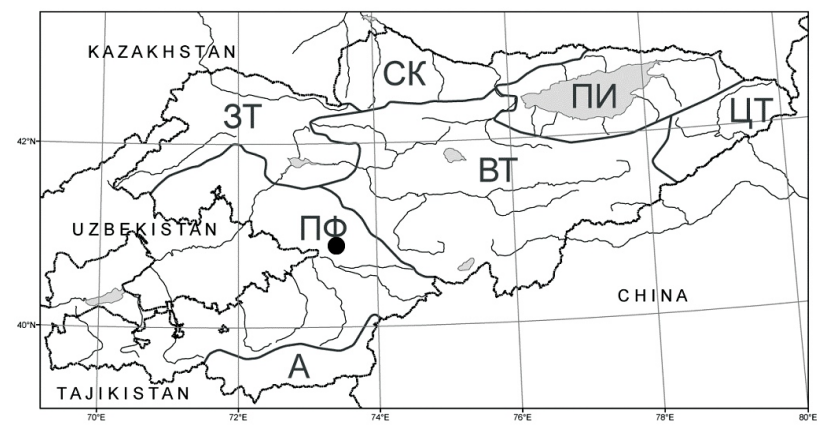

Карта 6. Alopecurus myosuroides

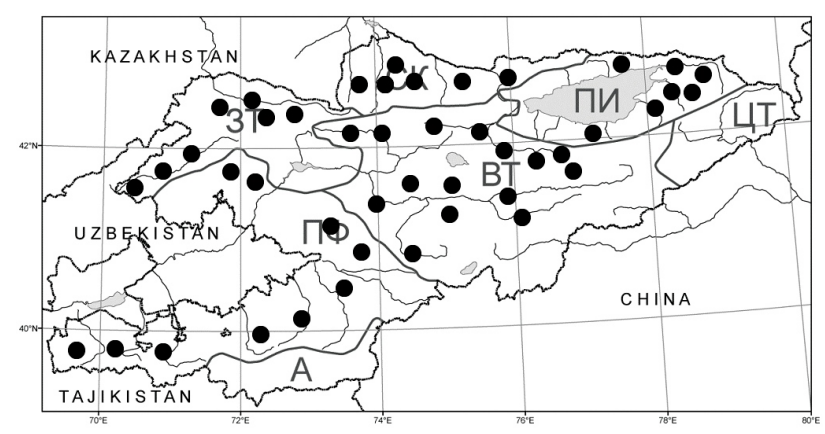

Карта 7. Alopecurus pratensis

Puc. Распространение видов рода Alopecurus L. в Кыргызской Республике 
(Bourg. ex Lange) Tzvel. 1976, Злаки СССР, 376, табл. 7, рис. 1. - Л. луговой.

Описан из Европы [19].

VI-VIII. Пояс долин низкогорий и предгорий, средний и субальпийский пояса гор; кустарники (полидоминантные, мезофитные листопадные), луга (пойменные, мезофитные, высокотравные, разнотравные), болота, берега рек, озер и водоемов, пески (приречные), галечники (приречные), солончаки.

Распространение - КР (Карта 7): СК, ПИ, ЗТ, ПФ, ВТ.

- Общее: Средняя Азия (ТШ, Арало-Каспий, Прибалхашье, Джунгар-Тарбагатай, Гисс.-Дарв., Памир), Кавказ, Западная Сибирь, Восточная Сибирь, Дальний Восток, Скандинавия, Атлантическая Европа, Средняя Европа, Восточная Европа, Средиземноморье, Малая Азия, Иран, Гималаи, Джунгар-Кашгар, Монголия, Япония-Китай, Южная Азия [19].

С е к ц и я 3 .Alopecurium Dum.

6. A. aequalis Sobol. 1799, Fl. Petrop. 16; Цвелев 1976, Злаки СССР, 379. - Л. равный.

Описан из Ленинградской обл.; возможный тип: «Flora Petropolitana» (LE) [19].

VI-IX. Пояс долин низкогорий и предгорий, средний пояс гор; болота, берега рек, озер и водоемов.

Распространение - КР (Карта 1): СК, ВТ.

- Общее: Средняя Азия (ТШ, Арало-Каспий, Прибалхашье, Джунгар-Тарбагатай, Памир), Кавказ, Западная Сибирь, Восточная Сибирь, Дальний Восток, Скандинавия, Атлантическая Европа, Средняя Европа, Восточная Европа, Средиземноморье, Малая Азия, Иран, Гималаи, Джунгар-Кашгар, Монголия, Япония-Китай, Южная Азия, Северная Америка [19].

Примечание. Новый вид для флоры КР. Согласно Н. Н. Цвелеву [19] данный вид распространен на Тянь-Шане, но где точно на территории КР неясно.

Изученные образцы. Сусамырская долина, пойма среднего течения р. Каракола Западного, в воде, 9.VII.1970, Горбунова; Ак-Сайские сырты, Восточный Ак-Сай, долина р. Балык-Суу, днище пересохшего водоема, 11.VIII.1965, Попова; АтБашинский район, бассейн р. Ат-Баши, высохщее озеро, 4.VIII.1932, Выходцев; Фрунзенская область, Кеминский район, хребет Кунгей Ала-Тоо, урочище Туюк, 3.VIII.1957, Исаков; Северный макросклон Нарынского хребта, примерно 50 км восточнее г. Нарын, Нарынский государственный за- поведник, склон левого берега реки Нарын, 10.VIII.2013, Лазьков.

С е к ц и я 4.Pseudophalaris Tzvel.

7. A. myosuroides Huds. 1762, Fl. Angl. : 23; Овчинников, 1934, во Флоре СССР, 2: 156, табл. 10, рис. 5; Набиев, 1968, в Определителе растений Средней Азии, 1: 94; Цвелев, 1976, Злаки СССР, 380. - Л. мышехвостниковидный.

Описан из Европы «in Europae pratis» [19].

IV-VII. Пояс долин низкогорий и предгорий; луга (пойменные), петрофитные группировки (каменистые, осыпи, щебнистые осыпи).

Распространение - КР (Карта 6): ПФ.

- Общее: Средняя Азия (ТШ зап., Сырдарья, Амударья, Гисс.-Дарв., Туркмения), Кавказ, Восточная Европа, Средиземноморье, Малая Азия, Иран, Гималаи [19].

\section{СПИСОК ЛИТЕРАТУРЫ}

1. Алексеев Е. Б. Род Овсянии (Festuca L.) в Средней Азии / Е. Б. Алексеев // Новости систематики высших растений. - 1979. - Т. 15. - С. 23-68.

2. Гамаюнова А. П. Alopecurus L. / А. П. Гамаюнова // Флора Казахской ССР. - Алма-Ата : Издательство АН Казахской ССР, 1956. - Т. I. - С. 170-174.

3. Дробов В. П. Alopecurus L. / В. П. Дробов // Флоpa Узбекской ССР. - Ташкент : Издательство АН Узбекской ССР, 1941. - Т. I. - С. 302-305.

4. Камелин Р. В. Ботанико-географические районы Киргизии / Р. В. Камелин // Зонтичные Киргизии. - Москва : KMK Scientific Press Ltd, 2002. - С. 1-18.

5. Красная книга Кыргызской Республики / под ред. А. А. Давлеткельдиева [и др.]. - 2-е изд. - Бишкек : Кыргызполиграфкомбинат, 2007. - 541 с.

6. Лазьков Г. А. Новые виды родов Festuca L. (Poaceae), Phlomoides Moench (Lamiaceae), Primula L. (Primulaceae) Acantholtmon Botss. (Limoniaceae) из Кыргызстана / Г. А. Лазьков // Новости систематики высших растений. - 2004. - Т. 36. - С. 28-39.

7. Лазьков Г. А. Кадастр флоры Кыргызстана: сосудистые растения / Г. А. Лазьков, Б. А. Султанова. - Бишкек, 2014. - $125 \mathrm{c}$.

8. Лазьков Г. А. Обзор рода Melica L. (Poaceae) во флоре Кыргызской Республики / Г. А. Лазьков, А. К. Усупбаев // Новости систематики высших растений. - 2017. - Т. 48. - С. 26-33.

9. Набиев Н. Н. Alopecurus L. / Н. Н. Набиев // Определитель растений Средней Азии. - Ташкент : Издательство ФАН Узбекской ССР, 1968. - Т. І. - С. 92-95.

10. Никитина Е. B. Alopecurus L. / Е. В. Никитина // Флора Киргизской ССР. - Фрунзе : Издательство АН Киргизской ССР, 1957. - Т. II. - С. 72-75.

11. Овчинников П. Н. Alopecurus L. / П. Н. Овчинников // Флора СССР. - Москва; Ленинград : Издательство АН СССР, 1957. - Т. II. - С. 148-156. 
12. Сидоренко Г. Т. Alopecurus L. / Г. Т. Сидоренко // Флора Таджикской ССР. - Фрунзе : Издательство АН Таджикской ССР, 1957. - Т. I. - С. 406-407.

13. Усупбаев А. К. Обзор видов рода Hordeum (Poaceae) в Кыргызской Республике / А. К. Усупбаев // Исследования живой природы Кыргызстана. - 2016. № 1-2. - С. 56-60.

14. Усупбаев А. К. Род Aegilops L. в Кыргызской Республике / А. К. Усупбаев // Известия Национальной академии наук Кыргызской Республики. - 2014. - № 1. - C. 36-42.

15. Усупбаев А. К. О двух видах рода Poa L. (Роасеае) из Кыргызской Республики / А. К. Усупбаев // Доклады Национальной академии наук Кыргызской Республики. - 2017. - № 2. - С. 37-42.

16. Усупбаев А. К. Новый вид и ключ для определения видов рода Trisetum Pers. (Роaceae) в Кыргызстане / А. К. Усупбаев // Известия Национальной академии наук Кыргызской Республики. - 2017. - № 2. - С. 31-34.

17. Усупбаев А. К. История изучения мятликовых (Poaceae) в Кыргызской Республики / А. К. Усупбаев // Изучение, сохранение и рациональное использование растительного мира Евразии. Казахстан. - Алматы, 2017. - C. 149-153.

18. Усупбаев А. К. Обзор видов рода Elymus L. (Роасеае) в Кыргызской Республике / А. К. Усупбаев // Вестник Воронежского государственного университета. Сер. Химия. Биология. Фармация. - 2018. - № 3. С. $112-120$.

19. Цвелев Н. Н. Alopecurus L. / Н. Н. Цвелев // Злаки СССР. - Ленинград, 1976. - С. 369-381.

20. Nobis M. Remarks on the taxonomy and nomenclature of the Stipa tianschanica complex (Poaceae), on the base of anewrecord or the flora of Tajikistan (central Asia) / M. Nobis // Nordic Journal of Botany. - 2011. Vol. 29(2). - P. 194-199.

21. Nobis M. Stipa narynica sp. nov. (Poaceae) from the western Tian-Shan Mountains / M. Nobis // Nordic Journal of Botany. - 2012. - Vol. 30(1). - P. 70-76.

22. Parolly G. Oreopoa gen. novum, two other new grasses and further remarkable records from Turkey / G. Parolly, H. Scholz // Willdenowia. - 2004. - Vol. 34. P. 145-158.

23. Zhang Z-S. Ptilagrostis contracta (Stipeae, Poaceae), a New Species Endemic to Qinghai-Tibet Plateau / Z-S. Zhang, L-L. Li, W-L. Chen // PLOS One. - 2017. Vol. 12, No. 1. - P. 0166603.

\section{REFERENCES}

1. Alekseev E. B. Rod Ovsyanitsa (Festuca L.) v Sredney Azii / E. B. Alekseev // Novosti sistematiki vysshikh rasteniy. - 1979. - T. 15. - S. 23-68.

2. Gamayunova A. P. Alopecurus L. / A. P. Gamayunova // Flora Kazakhskoy SSR. - Alma-Ata : Izdatel'stvo AN Kazakhskoy SSR, 1956. - T. I. - S. 170-174.

3. Drobov V. P. Alopecurus L. / V. P. Drobov // Flora Uzbekskoy SSR. - Tashkent : Izdatel'stvo AN Uzbekskoy SSR, 1941. - T. I. - S. 302-305.
4. Kamelin R. V. Botaniko-geograficheskie rayony Kirgizii / R. V. Kamelin // Zontichnye Kirgizii. - Moskva : KMK Scientific Press Ltd, 2002. - S. 1-18.

5. Krasnaya kniga Kyrgyzskoy Respubliki / pod red. A. A. Davletkel'dieva [i dr.]. - 2-e izd. - Bishkek : Kyrgyzpoligrafkombinat, 2007. - $541 \mathrm{~s}$.

6. Laz'kov G. A. Novye vidy rodov Festuca L. (Poaceae), Phlomoides Moench (Lamiaceae), Primula L. (Primulaceae) Acantholtmon Botss. (Limoniaceae) iz Kyrgyzstana / G. A. Laz'kov // Novosti sistematiki vysshikh rasteniy. 2004. - T. 36. - S. 28-39.

7. Laz'kov G. A. Kadastr flory Kyrgyzstana: sosudistye rasteniya / G. A. Laz'kov, B. A. Sultanova. - Bishkek, 2014. $-125 \mathrm{~s}$.

8. Laz'kov G. A. Obzor roda Melica L. (Poaceae) vo flore Kyrgyzskoy Respubliki / G. A. Laz'kov, A. K. Usupbaev // Novosti sistematiki vysshikh rasteniy. - 2017. T. 48. - S. 26-33.

9. Nabiev N. N. Alopecurus L. / N. N. Nabiev // Opredelitel' rasteniy Sredney Azii. - Tashkent : Izdatel'stvo FAN Uzbekskoy SSR, 1968. - T. I. - S. 92-95.

10. Nikitina E. V. Alopecurus L. / E. V. Nikitina // Flora Kirgizskoy SSR. - Frunze : Izdatel'stvo AN Kirgizskoy SSR, 1957. - T. II. - S. 72-75.

11. Ovchinnikov P. N. Alopecurus L. / P. N. Ovchinnikov // Flora SSSR. - Moskva; Leningrad : Izdatel'stvo AN SSSR, 1957. - T. II. - S. 148-156.

12. Sidorenko G. T. Alopecurus L. / G. T. Sidorenko // Flora Tadzhikskoy SSR. - Frunze : Izdatel'stvo AN Tadzhikskoy SSR, 1957. - T. I. - S. 406-407.

13. Usupbaev A. K. Obzor vidov roda Nordeum (Poaceae) v Kyrgyzskoy Respublike / A. K. Usupbaev // Issledovaniya zhivoy prirody Kyrgyzstana. - 2016. - № 1-2. S. 56-60.

14. Usupbaev A. K. Rod Aegilops L. v Kyrgyzskoy Respublike / A. K. Usupbaev // Izvestiya Natsional'noy akademii nauk Kyrgyzskoy Respubliki. - 2014. - № 1. S. 36-42.

15. Usupbaev A. K. O dvukh vidakh roda Poa L. (Poaceae) iz Kyrgyzskoy Respubliki / A. K. Usupbaev // Doklady Natsional'noy akademii nauk Kyrgyzskoy Respubliki. 2017. - № 2. - S. 37-42.

16. Usupbaev A. K. Novyy vid i klyuch dlya opredeleniya vidov roda Trisetum Pers. (Poaceae) v Kyrgyzstane / A. K. Usupbaev // Izvestiya Natsional'noy akademii nauk Kyrgyzskoy Respubliki. - 2017. - № 2. - S. 31-34.

17. Usupbaev A. K. Istoriya izucheniya myatlikovykh (Poaceae) v Kyrgyzskoy Respubliki / A. K. Usupbaev // Izuchenie, sokhranenie i ratsional'noe ispol'zovanie rastitel'nogo mira Evrazii. Kazakhstan. - Almaty, 2017. S. 149-153.

18. Usupbaev A. K. Obzor vidov roda Elymus L. (Poaceae) v Kyrgyzskoy Respublike / A. K. Usupbaev // Vestnik Voronezhskogo gosudarstvennogo universiteta. Ser. Khimiya. Biologiya. Farmatsiya. - 2018. - № 3. - S. 112 120.

19. Tsvelev N. N. Alopecurus L. / N. N. Tsvelev // Zlaki SSSR. - Leningrad, 1976. - S. 369-381. 


\section{A. K. Усупбаев}

20. Nobis M. Remarks on the taxonomy and nomenclature of the Stipa tianschanica complex (Poaceae), on the base of anewrecord or the flora of Tajikistan (central Asia) / M. Nobis // Nordic Journal of Botany. - 2011. - Vol. 29(2). - P. 194-199.

21. Nobis M. Stipa narynica sp. nov. (Poaceae) from the western Tian-Shan Mountains / M. Nobis // Nordic Journal of Botany. - 2012. - Vol. 30(1). - P. 70-76.

Усупбаев Адилет Кыдыкбекович

кандидат биологических наук, старший научный сотрудник лаборатории флоры института Биологии Национальной Академии наук Кыргызской Республики, г. Бишкек, Кыргызская Республика, E-mail: adilet.usupbaev@mail.ru
22. Parolly G. Oreopoa gen. novum, two other new grasses and further remarkable records from Turkey / G. Parolly, H. Scholz // Willdenowia. - 2004. - Vol. 34. P. 145-158.

23. Zhang Z-S. Ptilagrostis contracta (Stipeae, Poaceae), a New Species Endemic to Qinghai-Tibet Plateau / Z-S. Zhang, L-L. Li, W-L. Chen // PLOS One. - 2017. Vol. 12, No. 1. - P. 0166603.

Aedile K. Usupbaev

Candidate of Biological Sciences, Senior researcher of the flora laboratory of the Institute of Biology of the National Academy of Sciences of the Kyrgyz Republic, Bishkek, Kyrgyz Rebublic, E-mail: adilet.usupbaev@mail.ru 